\title{
The Development of Mathematical Logical Reasoning through Computer Programming: The Case of the Computer Programming Olympics for Basic Education Students
}

\author{
Marco Antonio Sandini Trentin, Ariane Pazinato, Adriano Canabarro Teixeira \\ Grupo de Estudo e Pesquisa em Inclusão, Universidade de Passo Fundo, Passo Fundo, Brazil \\ Email:trentin@upf.br, ariane.mileidi@gmail.com, teixeira@upf.br
}

How to cite this paper: Trentin, M. A. S., Pazinato, A., \& Teixeira, A. C. (2017). The Development of Mathematical Logical Reasoning through Computer Programming: The Case of the Computer Programming Olympics for Basic Education Students. Creative Education, 8, 81-94. http://dx.doi.org/10.4236/ce.2017.81007

Received: December 12, 2016

Accepted: January 14, 2017

Published: January 17, 2017

Copyright $\odot 2017$ by authors and Scientific Research Publishing Inc. This work is licensed under the Creative Commons Attribution International License (CC BY 4.0).

http://creativecommons.org/licenses/by/4.0/

\begin{abstract}
The challenging resignification and qualified appropriation of technologies are urgently needed in schools because they are constantly present in human life, and their use can be a determining factor in the development of the individuals and the exercise of citizenship. This paper presents the results of an investigation into developments in mathematical logical reasoning among students who participated in the Computer Programming Olympics for Students of Basic Education promoted by the Grupo de Estudo e Pesquisa em Inclusão Digital (GEPID) [Study and Research Group in Digital Inclusion] of the University of Passo Fundo. The Olympics consisted of challenges to be overcome by public school students between the 6th and 9th grades, using the programming software, Scratch. This research study has analyzed the 2013 and 2014 Olympics. Methodologically, this study adopts a qualitative approach, supported by participatory research methods and a focus group involving one of the participating teams. The instruments for data collection consist of observations, questionnaires, and interviews used to verify the students' improved mathematical abilities. The data analysis has taken, as its theoretical basis, Papert's constructionism (1997, 2007), Mortari (2001), and Pozo's characterization of learning (2002). At the end of the analytic process, we confirmed that programming software propitiates new forms of learning, significantly influencing the development of mathematical logical reasoning.
\end{abstract}

\section{Keywords}

Informatics Knowledge, Computer Programming, Educational Technology, Mathematical Logic, Educational Games 


\section{Introduction}

We are living in the age of digital technologies and complex societies, which have triggered changes in the ways we communicate, access information, and consequently regard knowledge (Lévy, 2010). Although we cannot disregard Brazilian social inequality and the fact that, even today, many people in our country lack access to such technologies, it is our duty as educators to research the potential of these new devices to contribute to high quality education.

Having such technologies at our disposal, we must urgently develop actions that promote understanding of the way they function, recognizing their potential in a wide range of areas, including education. It is essential to explore their potential to provide children with opportunities to improve their logical reasoning skills and develop creativity. Given the speed with which information travels, and the technological demands reinforced in today's society, we cannot afford to ignore available digital tools that can stimulate students' creative development, making them more autonomous and capable of re(creating) their own realities. It is therefore necessary to explore new digital learning experiences and design processes that can be implemented through digital technologies.

Although technologies are omnipresent in schools and in children's everyday lives, we believe that that current classroom methods do not allow children to fully benefit from the educational opportunities they offer. In particular, they do not learn programming, a model of literacy for the digital age. Computer programming is a tool that could be used to eliminate the gap that exists in education, by promoting the development of students' mathematical logical reasoning skills. According to Ubiratan D'Ambrósio (1998), "technology by itself does not imply a good education. But without any doubt, it is almost impossible to get a good education without technology".

In the current school context, we have observed that informatics laboratories offer less and less fascinating content, forcing students to look for more interesting and challenging alternatives. Computer programming presents a clear alternative; in particular, the programming software Scratch ${ }^{1}$, which offers students the chance to create interactive stories, games and animations, and to share their creations on the Internet. Learning to use programming software will help students understand mathematical and computational concepts, apply logical reasoning, and interpret data and evidence, among other capacities.

This paper brings together reflections on and the results of research carried out by the Grupo de Estudos e Pesquisas em Inclusão Digital (GEPID) [Study and Research Group in Digital Inclusion] at UPF [the University of Passo Fundo], which analyzed new perspectives on the use of programming software (specifically Scratch) among school-aged children. To achieve this, the group launched the Computer Programming Olympics for Students of Basic Education, which provided essential elements for the collection of data for this research study. In particular, this investigation has focused on the development of

${ }^{1} S c r a t c h$ is software that allows students to learn programming through the organization of blocks; it was developed by the Lifelong Kindergarten Group at the Massachusetts Institute of Technology's (MIT) Media Lab. Scratch's official website is: http://scratch.mit.edu. 
mathematical logical reasoning in students of basic education, as a result of the Computer Programming Olympics.

\section{Educational Informatics: The Potential of Computers in Education}

The need to integrate new digital technologies into the school curriculum is urgent and challenging, especially given that technologies, although a reality in human life, are currently underused or completely ignored in the educational environment. Their incorporation could be a determining factor in the development of individuals. In Papert's vision (2007):

Citizens of the future have to deal with challenges, facing an unexpected problem for which there is no pre-established explanation. We have to acquire necessary skills to engage in the construction of the new or then we will admit to a life of dependency. The true competitive capacity is the capacity to learn. We should not learn to give right or wrong answers. We have to learn to solve problems.

We believe that it is possible to stimulate creative processes in learning by using available technologies. When computers were first introduced in education, at the end of the last century, a few paradigms were created, among them, one that sees the computer as a teaching, memorizing machine for perpetuating traditional teaching methods. It is necessary to replace that approach with the search for a new paradigm - the purpose of this research study. It is also essential, as Xavier (2012) highlights, to offer different learning environments to human beings in their totality; such environments would focus on forming critical, creative, and autonomous citizens-intellectual individuals-by enabling them to access many different social and cultural aspects of learning.

The key issue in the implementation of new technologies to support education is that students must be interested and motivated to search for desired information, thus transforming the traditional paradigm of education as "bank deposit, factory", into education as a construction of significant types of knowledge. We understand that the use of computers in education should be addressed from a constructivist-interactionist perspective, as an instrument of learning through which the student actively performs and participates in the process of constructing types of knowledge by interacting with the tool.

From this perspective, a daily session of educational informatics in school can follow one of two paths: the traditional path, in which the computer is just a more sophisticated instrument for learning, used only to present texts or enable electronic consultations-what Cysneiros (1999) has described as "conservative innovation"; or a more challenging alternative path, whereby the computer is used as an instrument to develop cognition and learning. In the first case, the computer "programs the child", through its binomial question-answer structure; as the child does not learn how to use the machine, his or her relative position is diminished in the learning situation. In the second case, the child learns to use 
the machine to resolve problems, and as an important instrument to aid in the construction of knowledge. This second path takes advantage of computer programming environments developed for education (also called authorship software), including environments that use the LOGO language (Super Logo, Mega Logo, etc.), Alice, and Scratch, the latter used in this research.

We can approach Papert's ideas $(1985,1997,2007)$, when we consider the potential benefits offered by the LOGO language to children learning computer programming. For him, the child programs a computer by teaching it. By "teaching the computer how to think", children embark on a new exploration of the way in which they themselves think and act by constructing computer programs. This process involves several abilities, among them the form of logical reasoning needed to write the program's execution sentences. “Thinking about modes of thinking makes the child becomes an epistemologist, an experience that few adults have ever had" (Papert, 1997).

This interaction with programming, early in a child's life, enables him or her to develop abilities that today's adults never acquired when as children, or even as adults. In addition, the process of development happens naturally. "The metaphor of the computer as an entity that speaks a mathematical language places the apprentice in a new quality of relationship with an important domain of knowledge" (Papert, 1997).

Papert presents technologies as intrinsic elements in the life of this new generation, viewing the computer as a powerful tool that enables children to reach a new level of abstract thinking, and vehemently criticizing traditional forms of school teaching.

...computer is not only another powerful educational instrument. It is the only one that allows us to approach what Piaget and many others identify as the obstacle that should be transposed for the passage of child thinking into adult thinking [...]. Knowledges that were only accessible through formal processes can now be addressed concretely (Papert, 1997).

For this reason, we have emphasized the potential use of methodologies based on educational informatics, derived from the theoretical skeleton that Papert developed over 30 years ago, which provided a foundation for many other researchers in the field. It is also important to highlight the fact that, according to Rushkoff (2012):

...computers and networks are more than mere tools: they are living beings themselves. In contrast to a hammer, a pen or even a sledgehammer, a digital technology is programmed. That means it not only comes up with instructions for use, but also for how it works. And as those technologies come to characterize the future way we live and work, people who program will end up molding our world. And it is the digital technologies especially that will shape that modeling process, either with our explicit cooperation or without it.

Taking into consideration the points above, we consider that it very important 
to incorporate programming into pedagogical processes. The action of programming teaches much more than the creation of complex algorithms; it also develops abilities and capacities in problem resolution, as Gates et al. (1999) have reported in the video, O que as escolas não ensinam [ What Schools Do Not Teach]. Human beings, when they begin to program, create their own algorithms; they stop being mere users of the computer and start to become programmers. Thus, they become citizens with more freedom to create and express their ideas and convictions.

We chose to work with Scratch in the Programming Olympics and consequently in this investigation because its dynamic interface was attractive to students at the age of our participants; in addition, it offered a project-sharing network that made public the students' constructions. Since it is this paper's main object of analysis and study, it is worth mentioning that Scratch is a free software tool, available from its official website ${ }^{2}$, where one can find productions made in different parts of the world, as well as supporting materials and tutorials. It does not require previous knowledge of other programming languages and is ideal for people who are just beginning to program.

Scratch makes use of a simple, colorful, block form of programming that is well-suited to children and young people. It allows users to build projects that develop their mathematical and programming abilities, while enriching the development of group work, and deepening and defining mathematical concepts. According to the EduScratch portal $(2014)^{3}$, “the languages of programming targeted at children are an ideal path for very young programmers just entering the world of technical ability and trying to produce their first applications and animations". EduScratch (2014) also states that, in addition to software support learning, it develops several computer competencies relating to information, communication, critical reasoning, systemic thinking, identification, the formulation and resolution of problems, creativity, intellectual curiosity, and interpersonal skills, as well as collaboration, self-direction, accountability, adaptability, and an understanding of social liability.

When considering this innovative tool, we cannot close our eyes and deny that it has any contribution to make to education. The Programming Olympics project was developed to strengthen this contribution. By recognizing that it is important to strengthen the relationship between software and the development of mathematical logical reasoning, we have sought, through the Computer Programming Olympics for Basic Education Students, to introduce and encourage this practice in schools.

\section{Learning and the Development of Mathematical Logical Reasoning}

For this dialog about learning and the development of mathematical logical reasoning, we have introduced some authors to explain how children learn and develop cognitively. 
Kamii (1988) offers a synthesis of significant aspects of Piaget's work on children's cognitive development from birth. Although our investigation has focused on students in the final years of Basic Education $\left(6^{\text {th }}-9^{\text {th }}\right.$ grades in Brazil), it is important to understand not just how children of that age group develop, but also how they have been developing throughout their lives.

According to Kamii (1988), Piaget established a distinction between three kinds of knowledge: physical, mathematical logical and social knowledge. Physical knowledge is everything that children recognize by observation, including the characteristics of objects and external reality: whether an object is round, or thin; whether it falls through the air when dropped; and whether it makes a noise when it falls. Social knowledge involves conventions constructed by people, including the way we are supposed to act in society, words that should not be used, celebration and holiday dates, and all the rules of society that children must learn through the mediation of adults. However, all of these kinds of knowledge require children to adopt mental structures that allow the recognition of differences between one thing and another and the establishment of relationships and connections. The process of coordinating relationships is an internal process called mathematical logical knowledge. For Kamii (1988):

... when we are presented with a red plaque and a blue one, and we notice the difference, that difference is an example of mathematical logical thinking. The plaques are really passible through observation, but the difference between them is not. The difference is a relation mentally created by the individual that relates both objects. The difference is neither in one plaque nor in the other. If the person did not place the objects inside that relation, for them there would be no difference [...] The relation in which one person places the objects is a personal decision. (p. 14)

Children make progress in developing mathematical logical knowledge as they increase their capacity to coordinate different repertoires of relations, which they have mentally established. By coordinating actions that relate to objects, the child produces symbolic manipulation and deductive reasoning (Mattos, 2012). Piaget identified two kinds of abstraction in that process of development: the empiric and the reflective. The first kind of abstraction focused on the properties of objects that were part of external reality; the second kind looked at relationships that existed in the internal reality of the child (his or her mind). These abstractions co-existed in the child, with one helping the other.

To clarify these points, we will provide examples of these two kinds of abstractions using the idea of constructing a number, as suggested by Kamii (1988). Children initially learn numbers using concrete sets that aid that process of empirical abstraction (the knowledge of physical proprieties) and reflective abstraction (the knowledge of differences and the establishment of relationships). In other words, students observe sets of objects and start to establish the relations of order and inclusion. However, as the numbers grow and it becomes impossible to represent them by sets, reflective abstraction can act on their own. Having built the relationships, it is possible to understand that numbers such as 
$1,000,000,000,002$ might never be seen or counted.

Echoing Kamii's ideas, Mortari (2001) affirms that reasoning is related to the act of making inferences, which consists of manipulating information, and making connections using pre-existing information and any new information received. This involves structuring the order of thoughts to create new lines of information, hierarchizing, and creating an analysis that presents results conceived as new information. As has already been discussed, the capacity for reflexive abstraction opens doors for many other abilities in children.

This discussion suggests that education should offer situations that enable children to construct such mental structures. Such knowledge cannot be transmitted by adults, but must be internally built from an external interaction. According to Piaget:

Mathematical logical knowledge, including number and arithmetic, is constructed or "created" by each child from inside to outside, in the interaction with the environment, that is, mathematical-logic knowledge is not acquired directly from the environment by internalization, it is necessary to interact so that the child can internally construct that concept (Oliveira \& Rocha, 2011).

As discussed in the previous chapter, among various educational informatics options, computer programming is seen as a differentiated tool, which enables the total interaction of the child with a machine that creates "micro-worlds" that incorporate much mathematical and mathetic knowledge. According to Papert (2007), mathetic knowledge is attributing meaning to what we want to learn; given that principle, we can learn anything.

Giving things meaning is relating to them and creating connections between new elements using elements already constructed in our minds. It is a way of amplifying new repertoires of schemes that make our mathematical logical reasoning ability more and more complex.

\section{A Methodological Proposal for Research}

This qualitative methodological approach has been supported through participation and focus group research. Data collection instruments were presented to research subjects through questionnaires, in order to ascertain the reality and capacities they could develop. We also carried out interviews with students and teachers to verify the eventual manifestations of improved mathematical logical capacities; in addition, we carried out constant, exploratory observations of the Olympics, to obtain and record data for later analysis.

\subsection{Computer Programming Olympics for Students of Basic Education}

Our field research was carried out during two Computer Programming Olympics for Students of Basic Education. The objectives were as follows: to promote the introduction of computer programming in basic education, using Scratch; to 
create new ways of using informatics resources in schools to advance several areas of knowledge; to provide new challenges for students, targeting interdisciplinarity and approximating the role of a university through public education networks.

The Olympics had the participation of public school basic education students ( $6^{\text {th }}$ grade and above) from Passo Fundo and the surrounding region. Each school was able to enter a maximum of two teams, made up of a responsible teacher, an alternate teacher, three students, and two alternate students. Training consisted of a preparatory workshop, weekly challenges, and visits to participating schools.

During the competition, held in UPF facilities, the teams received guidance before the activities began, in the form of test challenges designed to minimize the tension caused by competing. The execution team (supervisors, evaluators, the support team, the elaboration board, and the Olympics organizing team) was presented, after which the following materials were distributed to the teams: sealed envelopes, each containing a pencil, eraser, pen, and sheets printed with the challenges.

During the competition, which lasted for two hours, teams decided when they had finished each question and sent their responses to be evaluated by the board, which reviewed them using the criteria set out in the regulations. If a question failed to meet specific criteria, the team in question could re-send the challenge for evaluation one time only.

Each team's challenge status was revealed on an electronic panel, as well as by means of a regressive electronic chronometer, so that the teams could monitor the time they had left to execute the activities.

Each team had access to two five-minute orientation sessions with their teacher-counselor and two student replacements to use in rotation. However, they could only take advantage of these orientation sessions and alternate participants 30 minutes into the competition. At the end, the team rankings were released, along with the winners and the final score. There were awards, trophies, and medals for first, second, and third places.

The 2013 Olympics had logical reasoning and mathematics as its special focus. Of the eight challenges included in the competition, three were adapted from the Olimpíada Brasileira de Matemática da Escola Pública ${ }^{4}$ (OBMEP) [Brazilian Public School Mathematics Olympics], and the rest were included to develop the reasoning skills of participating teams. The 2014 Olympics used an interdisciplinary approach. The challenges involved the animation of stories, musical sequences, games, and mathematical operations, designed to test the mathematical competencies explained in the Parâmetros Curriculares Nacionais (PCNs) [Brazilian National Curriculum Parameters] (BRASIL, 1998). In the first Olympics, 14 teams participated, totaling seventy students; in the second, there were 10 teams; totaling fifty students, came from the whole Passo Fundo region.

It is important to briefly describe the team that was chosen as a focus group ${ }^{4}$ http://www.obmep.org.br/. 
for this research study and to briefly explain the reasons for that choice. The Escola Estadual de Ensino Fundamental Dr. João Carlos Machado, from the municipality of Sarandi, in the State of Rio Grande do Sul, participated in both the 2013 and 2014 Olympics. In 2013, they entered a team called "Escola Machado", and in 2014, they entered two teams: "Escola Machado", made up of students from the previous year, and "Machado 2". This investigation has focused on the development of the "Escola Machado" team's mathematical logical skills across both years. Table 1 explains the structure of the team, and the way we have identified the subjects of this research. The teams were composed by the same students in the two years.

As we can see in Table 1, the students who participated in 2013 continued on to 2014, with no changes to the team. Teacher A was the informatics laboratory teacher and Teacher B taught mathematics.

\subsection{Categories of Analysis}

The data obtained was organized into categories of analysis, as described below; these were supported by theoretical references, in particular, Papert (1997; 2007), Mortari (2001), and Pozo (2002). Although theories were used to support research on constructivism, the use of informatics in education, and educational informatics, this research project sought, above all, to develop logical reasoning through programming. It was therefore possible to design five categories of analysis to demonstrate logical reasoning approaches of particular value in promoting creative thinking.

\section{Category 1: Structuring the Order of Thoughts}

This category involved creating lines of information, hierarchizing, and analyzing elements in order to present results that were conceived of as new information, according to Mortari (2001). According to Papert, the computer is a powerful tool that enables children to reach a new level of abstract thinking:

...it is not only another powerful educational instrument. It is the only one

Table 1. First and alternate students and counselors and alternate teachers during two computer programming Olympics for students of basic education-Team Machado.

\begin{tabular}{|c|c|c|c|c|c|}
\hline \multicolumn{3}{|c|}{ 1st Olympics-2013 } & \multicolumn{3}{|c|}{ 2nd Olympics-2014 } \\
\hline Name & Grade & Age & Name & Grade & Age \\
\hline \multicolumn{3}{|c|}{ Team Escola Machado } & \multicolumn{3}{|c|}{ Team Escola Machado } \\
\hline \multicolumn{3}{|c|}{ Teacher-Counselor: Teacher A } & \multicolumn{3}{|c|}{ Teacher-Counselor: Teacher A } \\
\hline Student C & 7th Grade & 13 Years & Student C & 8th Grade & 14 Years \\
\hline Student E & 7th Grade & 13 Years & Student E & 8th Grade & 14 Years \\
\hline Student A & 7th Grade & 13 Years & Student A & 8th Grade & 14 Years \\
\hline \multicolumn{3}{|c|}{ Alternate Teacher: Teacher B } & \multicolumn{3}{|c|}{ Alternate Teacher: Teacher B } \\
\hline Student B & 7th Grade & 14 Years & Student B & 8th Grade & 15 Years \\
\hline Student D & 7th Grade & 12 Years & Student D & 8th Grade & 13 Years \\
\hline
\end{tabular}

Source: Data compiled by the author, 2014. 
that allows us to approach what Piaget and many others identify as the obstacle that should be transposed for the passage of child thinking into adult thinking [...]. Knowledge that would only be accessible through formal processes can now be approached concretely (Papert, 1997).

\section{Category 2: Mathematical Logical Reasoning}

Pozo (2002) says that situations experienced today, "respond to a diversity of contexts and contents of learning that should be analyzed differently". The arguments above demonstrate that the imbalance between traditional forms of teaching and current innovations has a significant impact on the process of teaching and learning by creating a disconnect and allowing the interaction of two strategies to prioritize real and significant learning. In discussing this, Pozo (2002) has emphasized that:

a better knowledge of the functioning of learning as a psychological process can help us better understand and maybe overcome some of those difficulties, adapting the activities of instruction to resources, capacities and dispositions, always limited, both of who learns as of who has to teach.

\section{Category 3: The Act of Inferring}

For Mortari (2001), logic is the science that focuses on the study of the principles and methods of inference, having as its main objective the goal of determining in what conditions certain things follow-as consequences, coming from something-and in what conditions they do not. Logic is directly connected to the forms and uses of thinking, and to adequate reasoning made up of all the principles that shape human thinking. Given this perspective, it is possible to affirm that logic is not conceptualized as an art, but as a science.

\section{Category 4: Autonomy}

Autonomy, in the sense that Paulo Freire (1996) has defended it, is (in a certain way) one of the great objectives and challenges of education. It is not enough merely to transmit, pass on, and teach content. It is also necessary to show and demonstrate in practice how a theory can be applied. Yet, considering autonomy as an acquisition gained through individual experience, Régnier (2000, in the writings of Braga, 2012) argues, "the development of the autonomy of human beings [...] leads us to imagine that they can be, under a few conditions, their own educators", such a capacity, for the author, conflates the actions of self-evaluating and self-correcting.

\section{Category 5: Self-Evaluation}

Self-evaluating is directly connected to the capacity for autonomy, since, if the students know themselves better, they will be better able to deal with difficulties and exploit their abilities and capacities. This leads to the idea of metacognition: increased consciousness of cognitive experience and acquired knowledge, as described by Braga, 2012.

Departing from the methodological design that these research steps were based on, we have presented an analysis of the data, providing approximate answers to the research question above. 


\section{Analysis of the Results}

In addition to the data obtained through participation in the Olympics, further data was acquired through the use of a questionnaire and interviews, as mentioned in the chapter on methodology. An analysis of these is included below.

Analyzing the collected data related to Category 1, Structuring the order of thoughts, we verified that the students presented structured thinking-in other words, that they understood, when analyzing the challenges of the Olympics, that they would need to enlist a sequence of commands, and to analyze and verify that sequence to make sure it met the required criteria. We noticed members of the team creating a mental structure of what was going to happen, without any need for paper. They planned out what would happen, demonstrating that, in order to program, you have to think logically. They planned ways in which tasks would be carried out in a preferred order or sequence. For this reason, it has been possible to infer that the development of their ordered thinking structure evolved over time, and was visible in the development of challenges.

In analyzing Category 2, Expressing ideas in a logical and organized way, we have deduced and highlighted, drawing on the discussions of Teachers A and B, that the students' development of reasoning skills improved. This attribute was a significant, although not sole, contribution made by the Olympics of Programming. In other words, the students evolved in their ability to express ideas logically and in an organized fashion. This evolution can be seen in the development of the challenges; in the first Olympics, solutions to the challenges were not well structured, while in the second Olympics, the structure was much better. Improvements included using repetition links instead of describing all of the commands. The students understood how to apply variable concepts, using sensors as well as presenting well-structured and organized commands. A change was also reflected in the comments of students who emphasized the need to think and use reason to develop knowledge, while also paying close attention to small details. We observed some students noticing that interpretation was fundamental to the resolution of any activity, both in the Olympics and in class. They commented that the Olympics helped them improve their ability to interpret.

An analysis of Category 3, Act of inferring, makes the evolution of the team apparent; during the second Olympics, they were able to intervene to guide each other, understanding the consequences of their actions in relation to their goals. Teacher A pointed out a significant improvement in logical reasoning. It is clear to us that the competition helped to develop some competencies; this is confirmed in the reports of teachers, who argue that teamwork favors a series of abilities, among them self-control, self-confidence, autonomy, initiative, leadership, interpretation, and an understanding of when it is necessary to delegate tasks and accept divergent opinions. These principles inevitably lead to the act of inferring.

The analysis of Category 4, autonomy, shows us that the students experienced an evolution in autonomy, as Student A reports, by: "paying more attention to things and ... trying to relate causes so that I can do a better job". To justify that 
autonomy, one need only consider the positioning of Student $\mathrm{C}$ with regard to music programming; although he knew nothing about it, he understood the importance of learning. This process can be verified in the account of Teacher A, who said:

"his studying was not a musical study, it was a mathematical study of music, how he could put that into programming; he searched and did well on the test, so he noticed the importance. We could see the evolution of Student $\mathrm{C}$ in that, in the first Olympics he was very much like that, now he managed to make his way both in the Olympics and in life".

The teacher's reports on issues relating to the development of autonomy show that this evolution was apparent in the way students resolved challenges; the students clearly grew in the way they developed programming and verified whether or not it was correct-independently-by carrying out the steps themselves, autonomously.

In the analysis of Category 5, self-evaluation, we have emphasized the report of one student, who was questioned about his reaction to finding an error in the code:

“Then, every time I do something I never see it as good, I always have to go the extra mile. For me to self-evaluate, I have to read it, and check that there are no mistakes, and make sure I haven't made a mistake in the interpretation so that I won't have to redo everything, because I'd get a little angry. I am a very impatient person, but I try to do as well as possible, then I read to check for mistakes as many times as I need to, even though I have no patience, until I find the mistake”. Student A.

\section{Final Considerations}

As Papert (2007) has explained, throughout the centuries, the school system has "changed, but not to the point of substantially changing its nature", as has happened in other fields. A 19th century teacher in a classroom today would probably be able to conduct a class, but a doctor in a similar situation would hardly manage to perform an operation.

Considering the categories of analysis established for this study, we can conclude that in the first category, "structuring the order of thought", all of the students evolved in terms of the way they understood and were able to analyze the challenges presented in the Olympics, demonstrating growth between the first and second Olympics, especially when it came to developing the programming for each challenge. One can see from the way the Olympic challenges were constructed that the structure of the students' thought processes deepened and became stronger.

In the second category, "expressing ideas logically", we have found an evolution in student thinking, both in the Olympics and also in the classroom, where members of the team began to analyze their tasks more carefully before performing them, and to look more closely at perceptions, which until then had not 
made sense to them. We have found that the way students resolved the challenges of the second Olympics provides clear evidence in this category, where students structured their thinking in a clear and logical way to present their programs.

In our analysis of Category 3, the "act of inferring", we have emphasized our finding that members of the team acquired the ability to intervene on each other's behalf, thoroughly understanding the consequences of actions taken in the course of the competition. We therefore believe that the team acquired principles that led it to make sound inferences in the competition, and also every day in school.

In relation to Category 4, "autonomy", our analysis of students' growth revealed positive findings; we also cited their own perceptions on autonomy, a form of "metacognition" mentioned earlier in this paper. The students clearly demonstrate growth in this area, and were clearly aware of it-a competence that is already bringing the group good results.

Finally, in relation to Category 5, "self-evaluation", the members of the team demonstrated care and a degree of perfectionism in the activities they carried out. They sought to perfect their constructions and were extremely careful to not make mistakes during their analyses and interpretations, supervising themselves and each other. These students developed higher levels of perception by carefully evaluating their own work, discovering a new sense of pleasure and satisfaction when a challenge was carried out correctly.

Thus, by analyzing the five categories above and reviewing the collected data, were able to reveal the cognitive growth of these students, as well as their use of interpretation and reasoning to carry out challenges and activities in the classroom. The activities demand calmness, caution, astute interpretation, fast reasoning, and, above all, a student's ability to evaluate his or her own final result-abilities that are positively reflected in mathematical logical reasoning, our hypothesis at the beginning of this study.

We conclude that the use of programming software can help students learn several concepts, which are valuable, not only in academic work, but also in their everyday lives, conferring benefits both educationally and outside of school. Although we cannot prove that the Olympics of Programming was responsible for the changes these students experienced, we have strong reasons to believe that these events were an important influence, helping this target audience to develop. The Olympics influenced the development of logical reasoning in participants, a finding shown in our analysis of the collected data, in which teachers and students noticed and commented on significant changes.

It is therefore appropriate to affirm that digital technologies, especially programming software, can promote new forms of learning, modifying the relationship between teachers and students, between students and students, and between students and knowledge-in particular, mathematical knowledge.

\section{References}

Braga, M. (2012). The Elements of the Teaching-Learning Process: From the Classroom 
to Education Mediated by the Digital Technologies of Information and Communication (TDIC's).

http://site.ufvjm.edu.br/revistamultidisciplinar/files/2011/09/OS-ELEMENTOS-DO-P ROCESSO-DE-ENSINO-APRENDIZAGEM-DA-SALA-DE-AULA-\%C3\%80-EDUCA \%C3\%87\%C3\%83O-MEDIADA-PELAS-TECNOLOGIAS-DIGITAIS-DA-INFORMA \%C3\%87\%C3\%83O-E-DA-COMUNICA\%C3\%87\%C3\%83O-TDICs elayn.pdf

Brasil (1998). National Curricular Parameters (2nd ed.). Brasília, DF: MEC.

Cysneiros, P. G. (1999). New Technologies in the Classroom: Improving Conservative Teaching or Innovation?

http://www.pucrs.br/famat/viali/doutorado/ptic/textos/articles-106213 archivo.pdf

D’Ambrósio, U. (1998). Ethnomathematics: Art or Technique of Explaining and Knowing. São Paulo: Ática.

EDUScratch (2014). http://eduscratch.dge.mec.pt/

Freire, P. (1996) Pedagogy of Autonomy: Necessary Knowledge of Educational Practice. São Paulo: Paz e Terra, 1996.

Gates, B. et al. (1999). O que as escolas não ensinam. https://www.youtube.com/watch?v=FWNkrZ93DVM

Kamii, C. (1988). The Child and the Number: Educational Implications of Piaget's Theory for Acting Together with Schoolchildren Aged 4 to 6 Years (7.ed.). Campinas: Papirus.

Lévy, P. (2010). Intelligence Technologies. Rio de Janeiro: Ed. 34.

Mattos, S. M. N. (2012). The Development of Logical Mathematical Reasoning: Possible Affective Joints. http://www.uff.br/var/www/htdocs/dalicenca/images/artigo5.pdf

Mortari, C. A. (2001). Introduction to Logic. São Paulo, SP: UNESP.

Oliveira, P. A. \& Rocha, A. J. O. (2011). Logical Reasoning, Concepts and Parameters Establishment for Mathematical Learning.

http://docplayer.com.br/10035352-Raciocinio-logico-conceitos-e-estabelecimento-de-p arametros-para-a-aprendizagem-matematica.html

Papert, S. (1985). Logo: Computers and Education. Translation of José A. Valente, Beatriz Bitelman and Afira V. Ripper. São Paulo: Editora Brasiliense.

Papert, S. (1997). The Networked Family. Lisboa: Relógio D’água.

Papert, S. (2007). The Children's Machine: Rethinking School in the Computer Age. Ed. Rev. Porto Alegre: Artmed.

Pozo, J. I. (2002). Apprentices and Masters: The New Culture of Learning. Porto Alegre: Artmed.

Rushkoff, D. (2012). The 10 Essential Issues of the Digital Age: Schedule Your Future Not to Be Programmed by It. São Paulo: Saraiva.

Xavier, R. T. O. (2012). The “Constructor" Use of Computers Seeking the Development of Cooperation, Autonomy, and Self-Esteem.

http://www.inf.ufsc.br/ edla.ramos/orientacoes/oteroregina.pdf 
Submit or recommend next manuscript to SCIRP and we will provide best service for you:

Accepting pre-submission inquiries through Email, Facebook, LinkedIn, Twitter, etc. A wide selection of journals (inclusive of 9 subjects, more than 200 journals)

Providing 24-hour high-quality service

User-friendly online submission system

Fair and swift peer-review system

Efficient typesetting and proofreading procedure

Display of the result of downloads and visits, as well as the number of cited articles Maximum dissemination of your research work

Submit your manuscript at: http://papersubmission.scirp.org/

Or contact ce@scirp.org 